Review

\title{
Nuclear Reactors, their Types and Impact on Safety, Environment and Sustainability towards a Green Future
}

\author{
${ }^{1}$ Ayush Kumar A, ${ }^{2}$ Godwin Glivin, ${ }^{2}$ N. Kalaiselvan and ${ }^{3}$ V. Mariappan \\ ${ }^{1}$ Department of Chemical Engineering, National Institute of Technology Tiruchirappalli, Tamil Nadu, India \\ ${ }^{2}$ Department of Energy and Environment, National Institute of Technology Tiruchirappalli, Tamil Nadu, India \\ ${ }^{3}$ Department of Mechanical Engineering, National Institute of Technology Tiruchirappalli, Tamil Nadu, India
}

\author{
Article history \\ Received: 24-08-2020 \\ Revised: 14-10-2020 \\ Accepted: $29-10-2020$ \\ Corresponding Author: \\ Ayush Kumar A, \\ Department of Chemical \\ Engineering, National Institute \\ of Technology Tiruchirappalli, \\ Tamil Nadu, India \\ Email: Ayush.kumar376@gmail.com
}

\begin{abstract}
The current world is shifting rapidly towards clean energy sources due to the rapid depletion of fossil fuels. Also, as a solution to the extremely intense growing demand of energy across most of the countries and increasing pollution, nuclear energy is considered as a strategic alternative as it is both clean and does not pollute the environment. When compared with most other conventional sources of energy production currently being used, Nuclear energy emits a minuscule quantity of greenhouse gases and hence is environmentally friendly. In this study, several types of nuclear reactors are compared and with environmental pollution and safety as a deciding parameter. Sustainability of the nuclear reactors, their classification concerning safety and their radiation emissions are also reviewed.
\end{abstract}

Keywords: Environment, Nuclear Energy, Nuclear Reactor, Safety, Sustainability

\section{Introduction}

The population of the world today is 1900 times the global population 12 thousand years ago. The population at that time was approximately 4 million which equates to half of today's population of London. The population is one of the primary reasons for the increased demand for energy and other natural resources in the world. Hence, the demand for energy has increased globally, especially since the latter half of the 20 th century. In 2018, the global energy requirement grew by $2.3 \%$, which is the fastest speed in the past decade (Usmani et al., 2020). Hence, to solve the energy demands of the highly increasing population, we need to switch over to cleaner methodologies of energy production which also give a large amount of energy for an invested capital amount and should also not pollute the environment. One of the significant sources of pollution is the energy-producing powerhouses which release a lot of carbon dioxide, which is a matter of concern.

The world is hence moving towards renewable energy sources which are clean and green. However, there are several questions and challenges which arise for the production of clean, renewable energy regarding the practical nature of the energy sources and the scalability of the system. Several techniques of renewable energy production have been verified in laboratory level applications and experiments, but their large-scale application is doubtful as there are several economic and commercial reliability of these sources. Hence, the novel energy production methodologies like thin-film solar, algae-based diesel, cellulosic ethanol are not yet available to be entirely commercialized due to several challenges (Suman, 2018). The global emission of greenhouse gases (mainly from power generating industries) comprising of SOx, NOx etc., have led to a swift increase in the phenomenon of ozone layer depletion which causes global warming and has drastically affected both the biotic and abiotic components of the ecosystem.

Nuclear power is used to generate electricity and other forms of energy in several countries of the world. In facilities called Nuclear Reactors, the process of nuclear fission or fusion undergoes and the enormous energy released is used for generation of electricity. These reactors can be classified in different ways based on their core fuel, moderators, coolants. The most commonly used classification criterion is the "generation" of nuclear reactors, which hint towards the era they have been setup. In this study, several kinds of conventional and modern nuclear reactors are compared and their characteristics pertaining to safety and sustainability are highlighted. Figure 1 shows the number of operational as well as underconstruction nuclear power plants in the world for the major nuclear power-producing countries (IAEA, 2020). 


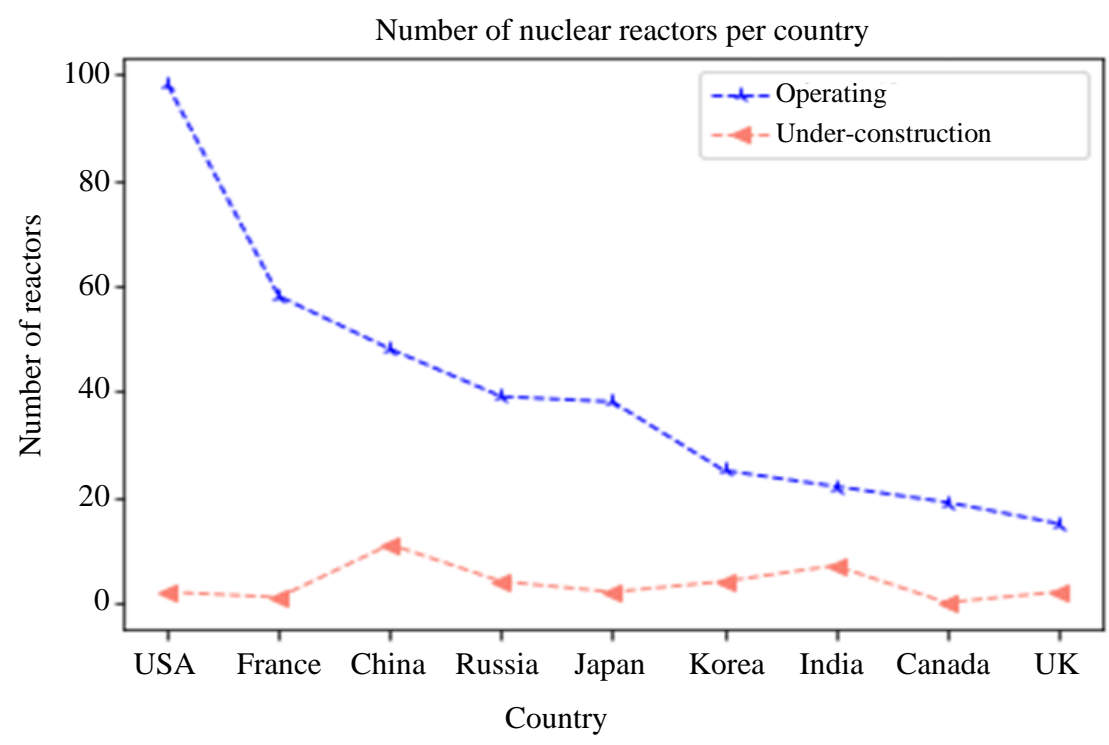

Fig. 1: Number of nuclear reactors per country

\section{History of Nuclear Energy}

From the ancient Indians and Greeks to modern scientists like JJ Thompson and Rutherford, the science of atoms has witnessed a lot of changes and ups and downs. Several breakthroughs have been made and the most significant one being made by Otto Hahn and Fritz Strassman, who discovered that Uranium atom breaks down if bombarded with neutrons and releases an enormous amount of energy. The mechanism of the chain reaction was proposed with the aid of the secondary neutrons produced in the first reaction, which later bombarded other atoms of Uranium and hence released even more energy. This energy if appropriately harnessed would bring a drastic change in the energy generation capacity of the planet and the same happened in this 21 st century, where the global nuclear power generation capacity is 350 GW (Hannah, 2014).

\section{Nuclear Safety}

There is a stigma in the minds of people regarding the safety and health issues of a nuclear plant set up in their country. The minds of the people are instilled with fear that the radiation that is emitted by the nuclear plants might cause them severe health issues, and it has been proven that the radiation is damaging to both humans and animals. There are several aspects to be considered for the safety of nuclear reactors. A few are discussed here.

\section{Classification of Reactors}

Nuclear reactors are broadly classified into four generations based on chronological order. Reactors of different generations have various support for safety and describe the development of nuclear reactors being used only for military purposes to their transition to energyproducing reactors for civilian purposes.

\section{Generation I}

These reactors were the earliest of all nuclear reactors. Mainly prototypes, these were the reactors which were shifted from military purposes like war to directly produce energy for civilian purposes without any significant changes and precautions for safety. In Europe, all the Generation I plants have been closed, the last one being at Wales.

\section{Generation II}

These systems were an improvement over the generation I plant which had an average lifetime of 40 years. Generation II plants were explicitly designed only for civilian uses like energy production and had taken special care for the safety and environmental issues. The Light Water Reactors (LWRs), which form the most substantial portion of operational nuclear reactors in the world come under this category.

\section{Generation III}

They are the hybrid reactors which were built after taking lessons from the Chernobyl accident in the Soviet Union. These reactors have a lifetime of 60 years and have many additional features for safety, making them highly secure and easier to operate. Pressurized Water Reactors (PWRs) and Boiling Water Reactors (BWRs) come under the category of Generation III nuclear reactors. 


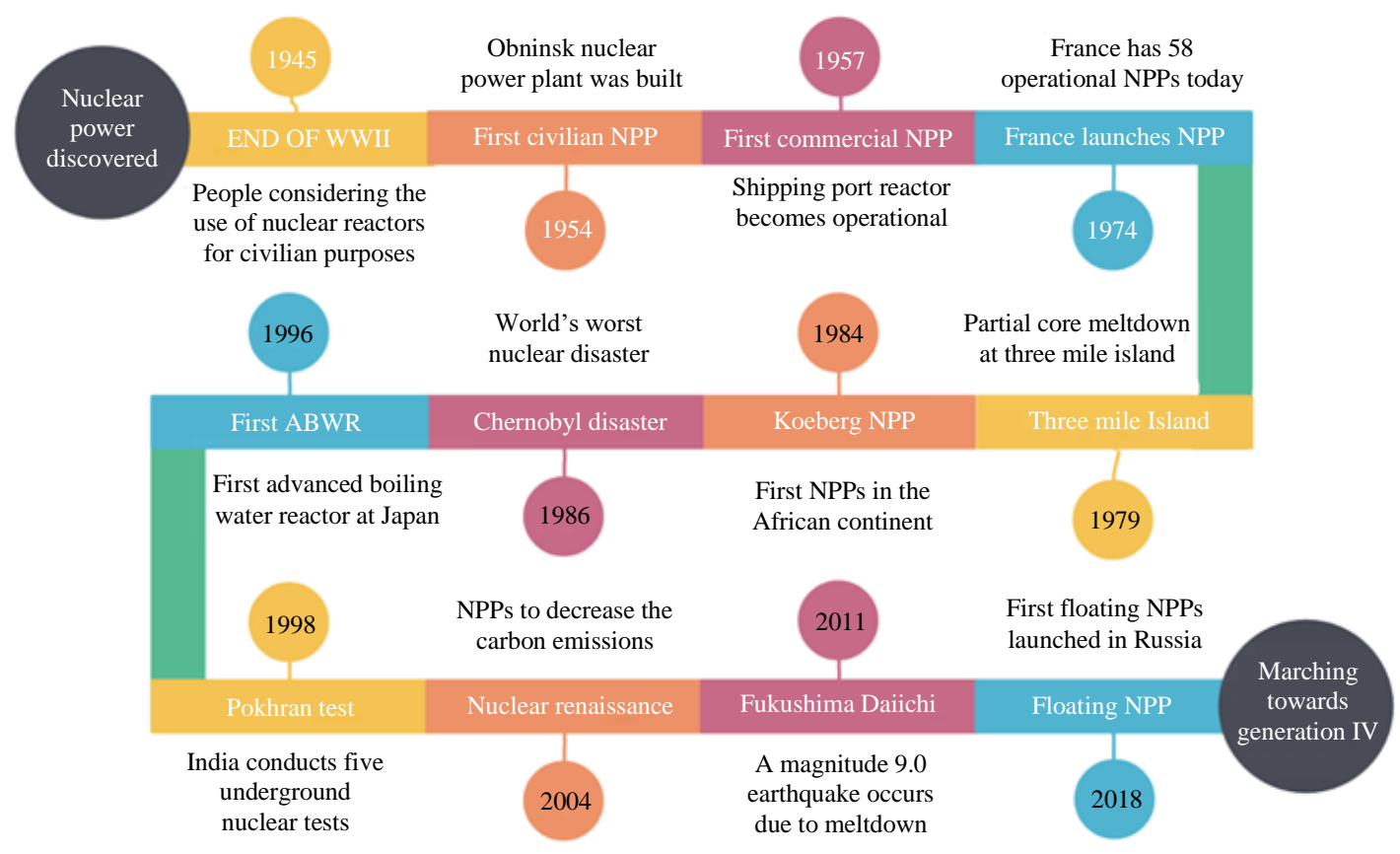

Fig. 2: Timeline of nuclear power advancements

Table 1: Design of nuclear reactors

\begin{tabular}{lllll}
\hline Parameter & $\begin{array}{l}\text { Available } \\
\text { technologies }\end{array}$ & Advantages & Disadvantages & References \\
\hline Design of nuclear & LWR & 1. Proven economics & 1. High risk & Abdulla et al. (2013) \\
reactor & SMR & 2. Widely used & 2. High cost & Budnitz et al. $(2018)$ \\
& & 1. Less radioactive core & 1. Economics is not proven & Mignacca and Locatelli (2020) \\
& & $\begin{array}{l}\text { 2. Small and can be } \\
\text { expanded easily }\end{array}$ & $\begin{array}{l}\text { 2. The need for } \\
\text { revolutionary design }\end{array}$ & Estrada-Domínguez et al. (2016) \\
\hline
\end{tabular}

\section{Generation IV}

These reactors are proposed as a radical change to the way of nuclear energy production mechanism. Perceived to be economical, safe and having the characteristics of all their successful predecessors, Generation IV nuclear reactors are still decades away from commercialization and universal application (Reinberger et al., 2019). Figure 2 shows the major events in the Nuclear history of the world.

The type of rector used in the Nuclear power plant also contributes a lot to safety. In the current situation, most of the reactors used in the world are Light Water Reactors (LWRs). These LWRs are historically being used because of established economics behind them, and they guarantee to be economical. But they come with high initial capital investment due to their enormous size and huge-power producing capacity, and there is also high risk involved with LWRs because of the enormous amount of power they deal with.

Table 1 shows the design and properties of various nuclear reactors.
The new countries which are looking forward to building a nuclear reactor have also considered Small Modular Reactors (SMRs) as they are comparatively safer than LWRs. SMRs are considered better than LWRs because of their proposed improved safety characteristics as compared to the conventional LWRs, affordable and economical nature due to their small size, and hence they have become a better match to the developing economies and are attracting a lot of research and development. However, a disadvantage of SMRs is that economics is not known and there is no certainty of standardizing the claims of SMRs.

\section{Specialized Types of Reactors}

Table 2 provides a comprehensive overview of several specialized reactors. Sodium Fast Reactor (SFRs) are the reactors which use Liquid sodium as a coolant, SFRs, due to their famous Sodium Void Reactivity Effect (SVRE) which can be used as effective actinide burners, hence generating less nuclear wastes, thus leading to a positive impact on the environment (Matveev et al., 2005). 
Table 2: Survey on types of nuclear reactors

\begin{tabular}{lllll}
\hline Reactor & Coolant & Moderator & Fuel & References \\
\hline SFR & Liquid Sodium & Water & Mixed oxide & Park (2017) \\
LFR & Pb-Bi Eutectic & None & Fertile uranium & Joyce $(2018)$ \\
HTGR & Helium & Graphite & Uranium & Ingersoll and Carelli (2014) \\
MSR & Fluoride, chloride, lithium & Graphite & Molten salt mixture & Dai $(2017)$ \\
PWR & Light water & Coolant $\mathrm{H}_{2} \mathrm{O}$ & Uranium dioxide & Breeze $(2016)$ \\
LWGR & Water & Graphite & Uranium Dioxide & \\
FNR & Water & None & 239Pu or ${ }^{238} \mathrm{U}$ & Gosset $(2017)$ \\
BWR & Demineralized water & Demineralized water & Uranium & Kerlin and Upadhyaya (2019a) \\
AGR & Carbon dioxide & Graphite & Uranium Dioxide & Tsvetkov (2016) \\
PHWR & Heavy water & Heavy water & Uranium & Kerlin and Upadhyaya (2019b) \\
\hline
\end{tabular}

Lead Fast Reactor (LFR) use a special eutectic of Lead and Bismuth as a coolant and do not require a moderator. One of the several advantages of the lead fast reactors is that after the initial fuel loading, on only natural Uranium is fed into the site, which significantly reduces the chances of pollution due to transportation and hence contributes to a sustainable environment (Alemberti, 2016). A comparative study of the behavior of an LFR and an SFR during a loss of flow event is highly critical for nuclear reactor safety. This has been shown by (Perez-Valseca et al., 2019). High-Temperature Gas Reactors (HTGRs) use helium as a coolant and are characterized by their safety and their feature of eliminating the core meltdown and also minimizing radioactivity release due to accidents. Since HTGRs have a helium environment and high temperature, they cause problems to the control rods due to the powerful radiation produced by such reactors. Hence, they are not as environmentally friendly as they emit excessive amounts of dangerous radiation (Beck and Pincock, 2011). Molten Salt Reactors (MSRs) are known for their molten salt mixture fuel which undertakes a variety of coolants and graphite moderators. MSRs are relatively safe and stable than other water-cooled reactors because of the fact that they do not experience high temperature and pressure. Hence, they work in a fairly less dangerous condition than other reactors which have water that is highly pressurized (Elsheikh, 2013).

Pressurized Water Reactor (PWR) is the most common type of nuclear reactors in the world and is known for its economical nature. They work with less fissile core and have several safety systems installed. In PWRs, the water which is used as both coolant and moderator remains at a very high pressure, which can lead to loss of coolant accidents. Nevertheless, these are very stable as they produce less power at high temperature. Light Water Graphite Reactor (LWGR) is most commonly used in Russia, and they have graphite moderators that are cooled by water. LWGRs, also known as Reaktor Bolshoy Moshchnosty Kanalny (RBMK). It was the one which was at the site of the Chernobyl nuclear reactor accident. These were designed and built by the Soviet Union and are still functional in some of the Nuclear Power Plants (NPPs). Boiling Water Reactor (BWR) is characterized by the core heating water, which boils to steam and energy is hence produced (Guerrero and Paredes, 2018). Some of the Advanced BWRs have extra safety and security mechanisms which make then secure and reliable, thus stopping any probable fuel leakage and hence offering several backup options in case of emergency (Obaidullah and Sarkar, 2015). To design a fuel lattice for BWRs, EspinosaParedes and Guzmán (2011) designed an algorithm which formulated a fuel lattice which was composed of enriched Uranium and gadolinium. Also, the heat and mass transfer during Hydrogen formation in nuclear reactors was studied that predicted several important aspects of accident specific design of nuclear reactors (Cázares-Ramírez and Espinosa-Paredes, 2016). Apart from these, Fast Neutron Reactors (FNRs) do not use moderators and are highly efficient in energy production. They usually produce 60 times the energy compared to other conventional reactors and use either Uranium or Plutonium as fuels. Research is going on for the development of FNRs, and the designs are expected to be built within two decades (WNA, 2020). Pressurized Heavy Water Reactors (PHWRs) are very much different from PWRs and are used mainly in India and Canada. They use Heavy Water (D2O) as a coolant and a moderator and can be operated using both Uranium and Thorium.

\section{Conclusion}

Nuclear power has been proven to be a reliable source of power generation without a large emission of greenhouse gases and other pollutants. It can definitely be said as the Energy of the Future. Nuclear power is a cleaner method of energy production, having one of the least per capita carbon dioxide emission. In this study, several nuclear reactors have been analyzed and compared. Their features, history, impact on the environment and further developments have been discussed. Also, nuclear power encompasses the minimum level of toxicity among other methods of energy production if used with care, 
and appropriate safety precautions followed. It is also the least sensitive to the climate of the place where the NPP is setup, hence proving to be an evergreen source of energy which has no geographical or political limitations. Hence, the soaring energy demand can be met using nuclear energy in both developed and developing countries across the world.

\section{Acknowledgement}

The authors would like to thank National Institute of Technology, Tiruchirappalli for providing the necessary platform and support for carrying out this research.

\section{Authors Contributions}

Ayush Kumar A: Preparing the Manuscript. Godwin Glivin: Designing of the research plan. N. Kalaiselvan: Guiding in research.

V. Mariappan: Overall supervision and checking.

\section{Ethics}

This article is original and contains unpublished works. The corresponding author confirms that all of the other authors have read and approved the manuscript with no ethical issues involved.

\section{References}

Abdulla, A., Azevedo, I. L., \& Morgan, M. G. (2013). Expert elicitation of the cost of small modular reactors. Proceedings of the National Academy of Sciences, 110(24), 9686-9691.

Alemberti, A. (2016). The lead fast reactor: an opportunity for the future?

Beck, J. M., \& Pincock, L. F. (2011). High temperature gas-cooled reactors lessons learned applicable to the next generation nuclear plant (No. INL/EXT-10-19329). Idaho National Laboratory (INL).

Breeze, P. (2016). Nuclear Power. Academic Press.

Budnitz, R. J., Rogner, H. H., \& Shihab-Eldin, A. (2018). Expansion of nuclear power technology to new countries-SMRs, safety culture issues and the need for an improved international safety regime. Energy policy, 119, 535-544.

Cázares-Ramírez, R. I., \& Espinosa-Paredes, G. (2016). Time-fractional telegraph equation for hydrogen diffusion during severe accident in BWRs. Journal of King Saud University-Science, 28(1), 21-28.

Dai, Z. (2017). Thorium molten salt reactor nuclear energy system (TMSR). In Molten salt reactors and thorium energy (pp. 531-540). Woodhead Publishing.
Elsheikh, B. M. (2013). Safety assessment of molten salt reactors in comparison with light water reactors. journal of radiation research and applied sciences, 6(2), 63-70.

Espinosa-Paredes, G., \& Guzmán, J. R. (2011). Reactor physics analysis for the design of nuclear fuel lattices with burnable poisons. Nuclear engineering and design, 241(12), 5039-5054.

Estrada-Domínguez, L. A., Espinosa-Paredes, G., Nuñez-Carrera, A., del Valle-Gallegos, E., \& Vázquez-Rodriguez, R. (2016). Progress and utilization of small nuclear reactors. Energy Sources, Part A: Recovery, Utilization and Environmental Effects, 38(16), 2362-2369.

Gosset, D. (2017). Absorber materials for Generation IV reactors. In Structural Materials for Generation IV Nuclear Reactors (pp. 533-567). Woodhead Publishing.

Guerrero, A. P., \& Paredes, G. E. (2018). Linear and Non-linear Stability Analysis in Boiling Water Reactors: The Design of Real-time Stability Monitors. Woodhead Publishing.

Hannah, L. (2014). Climate change biology. Academic Press.

IAEA. (2020). "Nuclear Share of Electricity Generation in 2019". IAEA.

https://pris.iaea.org/PRIS/WorldStatistics/NuclearSh areofElectricityGeneration.aspx

Ingersoll, D. T., \& Carelli, M. D. (Eds.). (2014). Handbook of small modular nuclear reactors. Elsevier.

Joyce, M. (2018). Nuclear Engineering: A Conceptual Introduction to Nuclear Power. ButterworthHeinemann.

Kerlin, T. W., \& Upadhyaya, B. R. (2019a). Boiling Water Reactors. In: Dynamics and Control of Nuclear Reactors. Academic Press.

Kerlin, T. W., \& Upadhyaya, B. R. (2019b). Pressurized heavy Water Reactors. In: Dynamics and Control of Nuclear Reactors. Academic Press.

Matveev, V. I., Yeliseev, V. A., \& Poplavskaya, Y. V. (2005, November). The Use of Sodium-Cooled Fast Reactors for Effectively Reprocessing Plutonium and Minor Actinides. In An International Spent Nuclear Fuel Storage Facility: Exploring a Russian Site as a Prototype: Proceedings of an International Workshop (p. 59). National Academies Press.

Mignacca, B., \& Locatelli, G. (2020). Economics and finance of Small Modular Reactors: A systematic review and research agenda. Renewable and Sustainable Energy Reviews, 118, 109519.

WNA. (2020). Nuclear Power Reactors. World Nuclear Association. https://www.worldnuclear.org/information-library/nuclear-fuelcycle/nuclear-power-reactors/nuclear-powerreactors.aspx 
Obaidullah, M., \& Sarkar, M. (2015). Safety Issues of Boiling Water Reactors.

Park, J. Y. (2017). SiCf/SiC composites as core materials for Generation IV nuclear reactors. In Structural Materials for Generation IV Nuclear Reactors (pp. 441-470). Woodhead Publishing.

Perez-Valseca, A. D., Quezada-Garcia, S., GomezTorres, A. M., Vazquez-Rodriguez, A., \& Espinosa-Paredes, G. (2019). Reactor behavior comparisons for two liquid metal-cooled fast reactors during an event of loss of coolant. Case Studies in Thermal Engineering, 16, 100556.

Reinberger, D., Ajanovic, A., \& Haas, R. (2019). The Technological Development of Different Generations and Reactor Concepts. In The Technological and Economic Future of Nuclear Power (pp. 243-258). Springer VS, Wiesbaden.
Suman, S. (2018). Hybrid nuclear-renewable energy systems: A review. Journal of Cleaner Production, $181,166-177$.

Tsvetkov, P. (2016). Gas-cooled fast reactors. In Handbook of Generation IV Nuclear Reactors (pp. 91-96). Woodhead Publishing.

Usmani, Z., Sharma, M., Gupta, P., Karpichev, Y., Gathergood, N., Bhat, R., \& Gupta, V. K. (2020). Ionic liquid based pretreatment of lignocellulosic biomass for enhanced bioconversion. Bioresource Technology, 304, 123003. 